\title{
The University's Role in the Development of Youth Entrepreneurial Culture
}

\author{
Tatiana M. Eldieva ${ }^{1 *[O R C I D ~ 0000-0002-1861-3732] ~}$
}

\author{
${ }^{1}$ Yaroslav-the-Wise Novgorod State University, Veliky Novgorod, Russia \\ Tatiana.Eldieva@novsu.ru
}

\begin{abstract}
One of the most promising areas of development of the country's economy is youth entrepreneurship. Its role and significance are being actively discussed in federal and regional circles, in the field of education and business. The ongoing changes in the economy determine the continuous accumulation and renewal of knowledge, the ability to use it in a variable manner, constant assessment of the situation and the adoption of responsible decisions in a rapidly changing external environment. Today one needs a specialist who not only possesses academic knowledge, but is also characterized by creative thinking, innovative approach, high technical and technological culture and is prepared for constant changes in the profession. One of the possible solutions to the issue under study is putting forward a hypothesis about the need for active involvement of the student audience in entrepreneurial activity. And the development of student entrepreneurship is one of the priority tasks of the state and the educational community. In recent years, Russian universities have been actively participating in the new agenda and joining the implementation of a program to attract talented youth and develop an ecosystem of technological entrepreneurship. To do this, it is necessary to take into account a whole range of various organizational, financial and technical components that will determine the relationship between all participants and ensure all stages of the development of the business environment. This indicates the need to create special conditions at the university and serious mechanisms for its implementation, starting with the organization of the process itself, document circulation and the entry of an entrepreneur into the market environment. This, in turn, will make it possible to form a system of institutions for the development of educated and highly qualified entrepreneurs as potential drivers for creating a strong economy in the modern world.
\end{abstract}

Keywords: small business, start-up, academic environment, university, entrepreneurial activity

\section{INTRODUCTION}

Increasing importance for the development of the Russian economy is the strengthening of the role of the small business sector. Small business today is a more adaptive and responsive business. Its potential contributes to the dynamic development of infrastructure, the commercialization of scientific research and the introduction of innovative technologies. The entrepreneurial initiative activates the emergence of new products, services and technologies on the market, creates new production methods.

Foreign experience shows that the leading role in the generation of entrepreneurship is played by universities as places where science and education are concentrated [1].
In Russia, the contribution of small and mediumsized businesses (SMEs) to GDP is $20 \%$, in the EU this figure is $40 \%$ higher than in Russia, in Japan and the USA it is $30 \%$ higher. By the end of 2024 , as part of the implementation of the national project "Small and Medium Business and Support for Individual Entrepreneurial Initiatives" [2], this figure should increase to $32.5 \%$, employment in this area should reach 23 million people, and by $2030-$ 25 million people.

According to the majority of experts, in the medium and long term, youth entrepreneurship can become one of the drivers for the development of small and medium-sized businesses. Today, according to the tax service, more than 17.5 thousand people aged 14-18 are engaged in entrepreneurship in Russia, of which more than 
1 thousand people are aged 14-15, which is undoubtedly a huge potential for the country's economy [3].

\section{MATERIALS AND METHODS}

Nowadays, one of the directions of development of small business in Russia is student entrepreneurship. In universities, the opportunity to present a startup for defense instead of a diploma paper is gaining more and more popularity. This is a relatively new and poorly studied format of defense in Russian universities. Now every university is forced to independently think over the formats of implementation, internal documentation, prescribe algorithms for actions and processes. It should be noted that there are no unambiguous recommendations and instructions; they may differ even within one university (for example, at different faculties).

The aim of the work is to summarize foreign and Russian experience of implementing entrepreneurial culture in the educational environment, which will allow to form a general idea and give recommendations on the educational design of student startups.

To achieve this goal, the following tasks were set:

- to study the issues of early entrepreneurial activity;

- to study foreign and Russian experience in the implementation of a new format for the defense of a diploma paper;

- to describe the specifics of the "diploma paper as a startup" program;

- to identify the problems and limitations in the organization and implementation of the program.

The study was based on various methods of statistical analysis, synthesis, the method of expert assessment and survey, empirical research, review and analysis of publications on the research topic.

\section{RESULTS}

In recent years, the issues of developing and stimulating the entry into the Russian economy of such a phenomenon as youth entrepreneurship [4] have become particularly relevant.

Expert assessments have shown that today, despite the COVID-19 pandemic, ambitious and positive-minded young people, after lockdowns and restrictive measures are lifted, are quicker than others to return to doing business, investing and developing.

This was also pointed out by the President of the Russian Federation V.V. Putin in his Address to the Federal Assembly of the Russian Federation dated April 21, 2021. The President noted that Russian youth have shown themselves worthily during the period of trials, it is making him proud and also that it is necessary to do everything possible to involve the younger generation in the development of the country. "It is necessary to ensure that every national project (program) includes activities aimed at supporting youth," the head of state emphasized [5].

One of the main directions of the implementation of youth policy is the Federal Law of December 30, 2020 No. 489-FZ "On youth policy in the Russian Federation" adopted at the end of 2020 (hereinafter - Law No. 489-FZ) [2], where support for youth initiatives is indicated, as well as the intent of promotion of youth entrepreneurship. In addition, general issues of youth policy, in terms of the joint jurisdiction of the Russian Federation and the constituent entities of the Russian Federation, are also reflected in the new Constitution of the Russian Federation (part 1 of article 72) [6]. Also, within the framework of the 2021 St. Petersburg International Economic Forum, the issues of supporting youth were once again identified.

A joint study on the assessment of entrepreneurial activity by the Global Entrepreneurship Monitor, the Graduate School of Management of St. Petersburg State University and PJSC Sberbank showed that in the period from 2014 to 2019 there was an increase in entrepreneurial activity. There was more than triple - from 4.4 to $14.5 \%$ - increase in the age group of 18 to 24 years old and almost double - from 9.8 to $19 \%$ - in the age group of 25 to 34 years old [7]. For example, in Moscow, there are about 13 thousand individual entrepreneurs under 25 years of age, another 50 thousand residents are founders and the same number are heads of companies.

In 2020, Russia outstripped some European countries by more than $7 \%$ in terms of early entrepreneurial activity. Thus, for example, Russia outstripped Sweden by $7.3 \%$, Norway by $7.6 \%$ and Great Britain by $7.8 \%$. Until 2016, Russia's lag was significant, low entrepreneurial intentions were demonstrated [8].

According to A. Gapon, manager of the practice of strategic and operational consulting at KPMG in 
Russia and the CIS, early entrepreneurial activity is facilitated by the transition of the economy to online. In Russia, the number of Internet users is increasing every year, today it has reached $81 \%$, while the world average is $59 \%$. Young people are getting into the habit of using digital technologies in their lives and professional activities, they are better aware of new trends, tendencies and ideas.

Annual research by the Agency for Strategic Initiatives (ASI) and the Center for Youth Initiatives shows that $88 \%$ of high school students and students want to develop a business or are already doing it. This provided a basis for lowering the minimum age threshold for registering as self-employed from 18 to 16 years [3]. If one considers foreign experience, then it runs counter to the Russian, so according to KPMG, in the United States, the share of youth in entrepreneurship over the past 25 years has fallen 2.5 times (from 10 to $4 \%$ ), in the EU it is also decreasing: over the past ten years - from 2.7 million to 2.5 million people [7].

However, further research showed that more than $50 \%$ of young people surveyed by ASI are afraid to start their own business due to a lack of knowledge and lack of business skills. Obviously, the question arises of the need to introduce into the education of young people not only disciplines in the chosen specialty, but also for them to acquire universal entrepreneurial skills. And the opportunity, along with a diploma, is to get a ready-made business.

Over the past decades, the world educational environment has changed markedly, universities are now not just translators of knowledge, but huge ecosystems where changes in the consciousness and thinking of students are designed and created. And the drivers of change are ideas, projects, startups - future entrepreneurs who are trained by universities [8].

Western universities have long been seriously competing in terms of "entrepreneurial opportunities" for students. For example, in Germany there is a "startup radar" rating, which determines the extent to which universities contribute to entrepreneurship. Let's analyze the ranking data and find out what universities offer their students [9].

So, in the first place is Munich Technical University (MTU). It is one of the global players in the international educational market. It has long been engaged in the development of entrepreneurship: firstly, for his students it provides start-up capital for starting a business; secondly, together with the Munich Graduate School of
Business, it provides training in 100 training courses in various areas of entrepreneurship; thirdly, it supports startups through a business incubator [10].

The experience of the Karlsruhe Institute of Technology is no less interesting; here, in addition to the already traditional entrepreneurial infrastructure, the program participants are also provided with a crowd funding platform. At it, student startups can be presented to potential partners and sponsors, and if the project interests the audience, it will be supported by collective investments [11].

Another striking example of a global leap in the development of an entrepreneurial culture is the University of Potsdam, where active entrepreneurs are involved in teaching practical skills.

And if the number of applicants approaches 15 thousand, is it worth it taking on such obligations for the university? Among these universities is the Leuphana University of Lüneburg, which is the first in this category. The university introduced new formats of education: immersion of freshmen in the basics of doing business within the framework of a five-day seminar, the creation of a Social Change Hub project for the development of social startups, the implementation of the Leuphana Business Accelerator competition - where the winners are guaranteed annual financial support.

The University of Oldenburg has jumped from the ninth position in the ranking to the second in the last three years. The main focus here is on awakening students' interest in doing business, for this, the Department of Entrepreneurship was created, the range of consultations was expanded, and support in finding sources of funding for projects was improved. Particular attention is paid to the development of entrepreneurship among women.

In other developed countries, universities are also establishing work on the development of entrepreneurial skills, opening situational centers, using case modeling and much more.

The main problem in the development of start-up education in many countries at the initial stage of development is the lack of investment support, in general, the synergy of young minds and experience, mutual assistance and work among like-minded people give a number of competitive advantages that form its uniqueness and ensure, as practice shows, the success of startups $[12,13]$.

Russian universities are just getting involved in the work of engaging young people in student entrepreneurship. More globally and on a large 
scale, the process of students entering into entrepreneurial activity began in 2020, and already since the start of the 2021 academic year, students from 48 Russian universities will have the opportunity to defend their diplomas in an unusual way - in the form of a startup [14].

The "Startup as a Diploma" program itself began its implementation in 2017; the Far Eastern Federal University (FEFU) is a pioneer in this direction. And in 2019, at the initiative of the Ministry of Science and Higher Education, together with ITMO University, this program was updated and work was carried out to scale the practice for educational institutions of higher education as part of the implementation of the federal project "Personnel for the Digital Economy" of the national program "Digital Economy of the Russian Federation" [15].

How to develop entrepreneurial competencies in students? Can all projects and should they all be presented for defense as startups? Let us consider the experience of pioneering universities.

As already noted, FEFU was the first to launch the "Startup as a Diploma" program in 2017. The result of four years of work was the introduction of project activities into teaching - as an important component of the educational activities of the university. The acceleration program is actively working, business events are held, and competitions are organized. All these are components of the entrepreneurial ecosystem that is developing at the university, which in the future enables students to defend their diploma paper as a startup.

In the 2020-2021 academic year, the university for the first time launched its own educational program with a competition of projects on a regional scale "Dalnevostochnyy start" ("Far East Start"). The graduates of this particular program were chosen as ones to defend their projects for the "Startup as a Diploma" program.

The university puts forward rather stringent requirements and criteria for the selection of student projects that can be presented for defense:

- the project must have a prototype or minimum viable product (MVP) at the time of release;

- the project must have financial resources (grants, investors, own funds, etc.) for the implementation of the project;

- the project must have the potential to scale.

At this stage, the program is not widespread, for all the time, 23 graduates got an opportunity to defend a startup, and every year there are more and more of them, for example, in 2021 there were already 16 of them. Today, the main goal of the program is aimed at involving only the most talented and enterprising students in technological entrepreneurship.

Graduates of the Southern Federal University (SFedU) can also defend their diplomas in the new format. This university, like many others, began to enter project activities and entrepreneurship by participating in the University 20.35 intensives and acceleration programs. SFedU experience shows that students need to be involved in work at all stages of project development, to demonstrate to them the importance and value of student initiative for society and self-realization. To give students the opportunity to meet with experts and entrepreneurs, receive feedback, and use interesting communication formats.

Tambov State Technical University (TSTU) joined the program in 2020. As a result, three student projects were submitted for defense. This result was preceded by years of operation of a business incubator at the university, in which students honed their entrepreneurial skills and presented the results in their diploma papers. TSTU also began with the development of project-based education, which subsequently gave impetus to the transformation of student ideas into business ideas and opportunities from implementation as a startup.

Yaroslav-the-Wise Novgorod State University is only on the way to the implementation of this program. The university's participation in projecteducational intensives has shown the potential, possibility and necessity of introducing projectoriented education among students of all directions and specialties. The university trained mentors, launched the work of student teams, and organized expert support for student projects. There is already a positive experience in the implementation of projects and their entry into the business component, the next stage is participation in the "Startup as a Diploma" program [16].

For the last 5 years, Russian universities have been experimenting with the "Startup as a Diploma" format. It allows one to present for defense instead of the classic final qualifying work a practical result in the form of an operating technological or other business. Separate islets of master's degree programs in technology entrepreneurship are emerging. Since 2021, the project "Startup as a Diploma" within the framework of the national program "Digital Economy" has become a part of education in 
universities in 25 regions. And since 2022, the Ministry of Education and Science of the Russian Federation plans to open start-up studios at universities across the country. It is assumed that students will even be able to take a year's leave from their studies to start their own business.

\section{DISCUSSION}

Working on a startup is not just writing a theoretical diploma paper, it is its special layout, making changes to the defense procedure, working with motivation for both students and teachers, using a large set of collaboration tools, and much more.

Universities that are already "experienced" in the implementation of startups point out the emerging difficulties and problems in the implementation of the program.

Firstly, it is noted that in order to defend the diploma project, the team members first need to make a general presentation of the startup, and then, in the usual format, present their individual part, as part of their educational program. If the team is interdisciplinary, then it is necessary to take into account the specifics of each discipline - after all, the state examination commissions are different for everyone.

Secondly, motivation in the student and teaching environment becomes a noticeable problem at the first stage of the project. The question of selection arises - not all students show entrepreneurial skills, and not all teachers are interested in participating in project activities. In addition, it is necessary to provide additional payment for the participants.

Thirdly, it turned out to be difficult to manage the program from the organization to the interaction of all users. A single digital space that would unite the whole set of tools used today is needed: Trello and Miro interactive whiteboards, different messengers for students and mentors, university LMS.

Fourth, for successful implementation, it is necessary to strengthen the business component of the program, including with the help of partners - to organize internships in various business structures and companies, to launch university preaccelerators, where student projects can prepare for specialized acceleration programs.

The result of the work should be not only the building up of competencies in the part of entrepreneurial activity, but also the training of those skills that allow one to turn knowledge into technologies and products [11].
Despite the fact that the "Startup as a Diploma" program has reached the federal level, uniform standards for its implementation have not yet been formed. Universities participating in the EduNet 2035 working group talk about a lack of common understanding, what does "startup as a diploma" mean? A large number of questions arise: what definition of "startup" should be used, what criteria should be taken as a basis? Today there is no common field for exchange of experience, and there is no base on which one could rely. To get answers to these questions, representatives of the PRE.INC project conducted a study, in the course of which the heads of 48 universities were interviewed that are already accepting startups for defense. Here's what the research results demonstrated:

1) There are no clear requirements for the program of defense of startup as a diploma project. There is no single formalized set of documents, procedures, processes and methodology that could be scaled up. Each university decides for itself how to fit this format into the educational process. Often within the same university, regulations may differ for different departments. In many universities, it looks like an individual undergraduate track - because of the disordered workflow, each participant is treated as a separate project.

2) Almost always the program implies two defenses. The startup itself is defended separately, and the diploma paper written on its basis is also presented for defense separately. The only exception to this rule, according to the research, is FEFU.

3) There is a shortage of competent personnel within universities, there is no one to lead the program, to be a mentor, which in the future leads to the fact that students' projects "do not live" after graduation. Teachers simply do not know where to send them, and it is not always possible to attract trackers with entrepreneurial experience from the real business environment.

4) Often teachers resist innovations and ignore the curriculum. Most often this is due to ignorance of the acceleration processes.

5) Students are not motivated to participate in the program. Sometimes they are scared off by the complex and unfamiliar phrases "technological entrepreneurship", "prototype", "technologies", "inventions" and 
"product" - they think that this is something complicated, difficult to implement.

What do universities go to when solving these problems? According to P. Avanyan, managing partner of Center-game.com, Preinc.ru and expert of the EduNet market, there are two extremes:

- if there is not a lot of experience in the development of youth entrepreneurship, these universities rely on external infrastructure commercial employee development programs, regional and federal competitions;

- those who have their own entrepreneurial ecosystem shut themselves in and develop their own approaches, courses and platforms, while outside experts are only attracted to a point; these are, as a rule, the "foremost workers" who launched the program in 20172018.

Limitations can be seen in both variants. In the first case, the focus on external programs and competitions leads to the fact that internal expertise within the university is poorly formed - students and employees participate everywhere, fulfill the targets of other organizations, but change the internal environment slowly. In the second case, the university inevitably hits the "ceiling" in scaling: one wants to increase the funnel of attracting students and projects to the program, but inside the university there is no longer enough human resources to work with them.

The solution is seen in the creation of platforms for the exchange of experience among program participants and the launch of additional training courses for teachers Such sites can arise, for example, within the community of EduNet market participants [14].

\section{CONCLUSION}

Academic entrepreneurship is gaining a leading position in the educational environment, and its importance increases especially when start-ups created by students and alumni begin to influence the economies of their countries. Examples of such successful entrepreneurial education are the famous graduates of the Massachusetts Institute of Technology and Stanford University, they are leaders and innovators, people who were "black sheep", were not afraid to think outside the box and show their creativity. Foreign studies show that only $5 \%$ of the population have an innate propensity for entrepreneurial activity [17].
Undoubtedly, business education at the university and beyond it differs significantly, but the world's best business schools and the best universities have a lot in common. First, they create a special entrepreneurial environment where people with common interests and values connect. Second, they are engaged in educating people who are able to think freely and make choices. And third, they provide a wide flow of knowledge. There is an opinion that it is impossible to teach entrepreneurship, but in this case, it is more important to understand the entrepreneurial culture and the possibility of transforming oneself and one's business to new realities.

A new generation of universities: this is the generation of people, knowledge and technology, which allows the student to be a universal professional in their field after the graduation. Students, including future entrepreneurs, must choose their educational trajectories themselves, like their universities, focusing on their missions, values and cultural codes.

Today, universities are faced with the task of "growing" future entrepreneurs, giving them the opportunity to show initiative. The created university entrepreneurial environment will allow them to possess critical thinking, broad professional knowledge and a desire to solve the most difficult problems. In addition to business skills, personal qualities are formed, which is the motivation for further growth and development.

Training the new generation of entrepreneurs is one of the primary tasks of all spheres and levels of government, and universities are becoming guides to the real world of small business. The academic environment should include three levels of training:

- the first level involves the creation of a general university environment that motivates students' interest in entrepreneurship (elective courses, simulators, simulators, open lectures);

- the second level is aimed at creating a special environment together with industrial partners for the formation of students' entrepreneurial skills (networking, cases, projects);

- the third level gives students the opportunity to proceed to real startups; this is the creation of a university ecosystem with a large-scale entrepreneurial infrastructure (accelerators, business incubators, business schools).

The university community should enable students to develop their talents in a comprehensive 
manner, not only to work for hire, but also to try to become an entrepreneur. And this is possible by creating an appropriate ecosystem in universities, institutes and public organizations. This process should become seamless, provide all opportunities for growth, and startups and accelerators should be right beside the students.

\section{REFERENCES}

[1] G.A. Reznik, Yu.S. Ponomarenko, "Student business as an important factor of innovation economy formation", University Management: Practice and Analysis, 2010, vol. 2, pp. 62-67. (In Russ.).

[2] Government of the Russian Federation, Federal Law "On youth policy in the Russian Federation” (December 30, 2020 No. 489). Moscow, 2020. (In Russ.).

[3] Most schoolchildren and students want to try themselves in business, 2021. Retrieved from https://regnum.ru/news/society/3288208.html

[4] E.A. Vetrova, E.E. Kabanova, N.V. Medvedeva, E.E. Jukova, "Management of Educational Services Promotion in the Field of Higher Education (the Example of "Russian State Social University")", European Journal of Contemporary Education, 2019, vol. 8(2), pp. 370-377. DOI: 10.13187/ejced.2019.2.370

[5] President of Russia, Message of the President of the Russian Federation to the Federal Assembly of 04.21.2021. Moscow, 2021. (In Russ.).

[6] Government of the Russian Federation, "Constitution of the Russian Federation (part 1 of article 72)" (July 01, 2020). Moscow, 2020. (In Russ.).

[7] I.N. Shafranskaya, "Can We Teach an Entrepreneur: Factors That Form Students' Entrepreneur Intentions”, University Management: Practice and Analysis, 2019, vol. 23(3), pp. 79-93. DOI: 10.15826/umpa.2019.03.021

[8] Yu.V. Shikhova, M.A. Konovalova, E.A. Lebedeva, "Integration of educational models of digital and classical universities", The European Proceedings of Social \& Behavioural Sciences, 2019, pp. 414-422. DOI: 10.15405/epsbs.2019.12.05.50

[9] G.V. Shirokova, T.V. Belyaeva, K.A. Bogatyreva, D.M. Knatko, et al., "Factors in the formation of students' entrepreneurial activity", St. Petersburg: Publ. house of St. Petersburg State University, 2016. (In Russ.).

[10] T. Wyman, "The best universities on the startup radar", 2017. (In Russ.). Retrieved from https://Top universities on the "startup radar" Deutsche Welle multimedia publications in Russian [Luchshie vuzy na "startap-radare" Multimedijnye publikacii Deutsche Welle na russkom yazyke] | DW | 06.03.2017

[11]M.N. Dudin, V.V. Bezbakh, E.E. Frolova, M.V. Galkina, "The Models of Higher Education in Russia and European Countries at the beginning of the XXIst century: the Main Directions of Development", European Journal of Contemporary Education, 2018, vol. 7(4), pp. 653-667.

[12]O.S. Bersan, C.M. Țîru, I.A. Dumitru, "Formative assessment and feedback "ingredients" for an effective and durable learning", The European Proceedings of Social \& Behavioural Sciences, 2018, vol. 63, pp. 448462. DOI: $10.15405 /$ epsbs.2019.06

[13]M.V. Gruzdev, I.V. Kuznetsova, I.Yu. Tarkhanova, E.I. Kazakova, "University Graduates' Soft Skills: the Employers' Opinion”, European Journal of Contemporary Education, 2018, vol. 7(4), pp. 690-698. DOI: 10.13187/ejced.2018.4.690

[14] "Startup as a diploma": what it is and where it is applied, 2021. (In Russ.). Retrieved from https://skillbox.ru/media/education/startap-kakdiplom-chto-eto-takoe-i-gde-primenyaetsya/

[15] The list of universities participating in the "Startup as a Diploma" project includes 48 universities, 2020. (In Russ.). Retrieved from https://www.profguide.io/news/spisok-vuzovstartap-kak-diplom.html

[16] Yu.V. Daneikin, O.E. Kalinskaya, N.G. Fedotova, "Project approach to the implementation of an individual educational trajectory in a modern university", Higher Education in Russia, 2020, vol. 8/9(29), pp. 104-116. DOI: 10.31992/0869-3617-202029-8-9-104-116

[17]D.F. Kuratko, "The emergence of entrepreneurship education: development, trends and challenges", Entrepreneurship Theory and Practice, 2005, vol. 29, pp. 577-598. DOI: $10.1111 /$ j.1540-6520.2005.00099 